\title{
JOSE DE LA CUADRA: NICASIO SANGURIMA, UN PATRIARCA OLVIDADO
}

\author{
POR \\ GALO F. GONZALEZ \\ Macalester College
}

Hace más de una década, dos conocidos escritores latinoamericanos señalaron que Los Sangurimas (1934), novela corta de José de la Cuadra (1903-1941), era un antecedente literario de Pedro Páramo (1955), de Juan Rulfo, y de Cien años de soledad (1967), de Gabriel García Márquez ${ }^{1}$. Jorge Icaza (1906-1978) lo aseveró durante una entrevista con Emmanuel Carballo en $1970^{2}$. Un año después, Fernando Alegría corroboró lo aceptado por Icaza y sugirió que algunos críticos «devotos de los Buendía le den una buena mirada a Los Sangurimas de José de la Cuadra» ${ }^{3}$.

Este consenso, al parecer, no es caprichoso. Las tres obras citadas presentan a un patriarca o a un cacique que domina un espacio y tiempo específicos: Nicasio Sangurima rige en «La Hondura», Pedro Páramo impera en Comala y José Arcadio Buendía se impone en Macondo.

${ }^{1}$ Pedro Páramo, 9. ${ }^{a}$ ed. (1955; reimp., México: Fondo de Cultura Económica, 1968); Cien años de soledad, 25. ed. (1967; reimp., Buenos Aires: Editorial Sudamericana, 1971). Todas las citas posteriores de Cien años se tomarán de esta edición.

${ }^{2}$ Protagonistas de la literatura hispanoamericana del siglo XX (México: UNAM, 1986), p. 43. Ante la siguiente declaración de Carballo: «Yo creo, don Jorge, que Los Sangurimas es un antecedente de Pedro Páramo y de Cien años de soledad», Icaza responde con un categórico «Sí». Y luego añade: «Por supuesto que sí, estoy de acuerdo.»

3 «Diálogo con Fernando Alegría: Novelas, novelistas y críticos», en Nuevo Mundo, núm. 56, París, febrero de 1971, p. 45. Con respecto a esta cita, consúltense: Humberto E. Robles, "Génesis y vigencia de Los Sangurimas», en Revista Iberoamericana, vol. XLV, núms. 106-107 (enero-julio de 1979), p. 86, y Narradores ecuatorianos del 30: J. Gallegos Lara, E. Gil Gilbert, A. Aguilera Malta, Pablo Palacios, Jorge Icaza, A. Pareja Diezcanseco, prólogo de Jorge Enrique Adoum, selección y cronología de Pedro Jorge Vera (Caracas: Biblioteca Ayacucho, 1980), p. XXxviII. La novela Los Sangurimas aparece reproducida en esta edición. Todas las citas posteriores que se refieran a la novela se tomarán de esta antología. 
Contados son los críticos que han dedicado tiempo y vigor al análisis de los posibles puntos de contacto existentes entre Pedro Páramo y Cien años de soledad ${ }^{4}$. Por otro lado, la novela de José de la Cuadra, a causa de la fecha de su publicación (1934) y por el asunto de que trata (la realidad social del montuvio), ha sufrido quizás de un olvido no intencionado. Cualesquiera que sean las similaridades que Los Sangurimas guarde con las novelas de Rulfo y de García Márquez, quedan por investigarse. No existe, que se sepa, un trabajo que específicamente haya llevado a cabo esta tarea ${ }^{5}$.

Los manuales y antologías de la novelística latinoamericana han elogiado la obra de José de la Cuadra en cuanto que ésta representa un manifiesto de la literatura de denuncia dentro de la «corriente del realismo regionalista» ${ }^{6}$. No llegan a más.

Se propone, aquí, la realización de un análisis preliminar que examine una posible relación de antecedencia entre Los Sangurimas y Cien años de soledad. De ninguna manera se ignora el peligro que acusa tal tarea. Se entiende y se respeta el exclusivo valor literario que acompaña a cada una de estas obras. Tampoco se ignora los años que las separan ni el ambiente literario alrededor de su creación y publicación.

Existe un factor favorable que alienta nuestro estudio. José de la Cua-

${ }^{4}$ Suzanne Jill Levine, El espejo hablado (Caracas: Monte Avila, C. A., 1975), particularmente el capítulo II, pp. 27-41. Este es un estudio, aunque breve, muy agudo y minucioso sobre el paralelismo que existe entre las dos novelas mencionadas de Rulfo y de García Márquez.

${ }^{5}$ Los trabajos consultados sobre la literatura ecuatoriana no dan referencias bibliográficas sobre este asunto. Véanse: Angel Rojas, La novela ecuatoriana 1948 (México: Fondo de Cultura Económica, 1948); Hugo Alemán, Presencia del pasado (Quito: Editorial de la Casa de la Cultura Ecuatoriana, 1953); J. Barrera Isaac, Historia de la literatura ecuatoriana (Quito: Editorial de la Casa de la Cultura Ecuatoriana, 1961); Galo René Pérez, Pensamiento y literatura del Ecuador (Quito: Editorial de la Casa de la Cultura Ecuatoriana, 1927); Antonio Sacoto, La nueva novela ecuatoriana (Cuenca: Publicaciones del Departamento de Difusión Cultural de la Universidad de Cuenca, 1981); Miguel Donoso Pareja, Los grandes de la década del 30 (Quito: Editorial El Conejo, 1985).

${ }^{6}$ Cabe mencionarse los siguientes: Benjamín Carrión, El nuevo relato ecuatoriano. Crítica y antología, 2. ${ }^{\text {a }}$ ed. (1951; reimp., Quito: Editorial Casa de la Cultura Ecuatoriana, 1958), pp. 127-128; Fernando Alegría, Historia de la novela hispanoamericana, 3. ${ }^{a}$ ed. (1959; reimp., México: Ediciones Andrea, 1966), p. 267; Enrique Anderson Imbert, Historia de la literatura hispanoamericana, II. Epoca contemporánea, 6." ed. (1954; reimp., México: Fondo de Cultura Económica, 1977), p. 266; Jean Franco, Spanish American Literature since Independence (London: Ernest Benn Limited, 1973), p. 161; Narradores ecuatorianos del 30, pp. Xxxv y ss., y Giuseppe Bellini, Historia de la literatura hispanoamericana (Madrid: Editorial Castalia, 1985), p. 518. 
dra y Gabriel García Márquez son dos escritores que comparten una misma preocupación: el amor a su tierra natal y el gustoso deseo de llevar a la ficción la realidad ingrata de los pueblos de su país, para enseñarnos a apreciarlos y a entenderlos como son, no como quisiéramos que fuesen. Jorge Enrique Adoum capta con acierto la preocupación literaria de José de la Cuadra:

Cuadra es de los raros de su generación que comprendieron que el compromiso con su época - con cualquier época- debía ir unido el compromiso con la literatura: y él cumplió ambos. Y como 'la realidad es más que suficiente', no trató de 'demostrar' nada ni se contentó con 'mostrar' esa realidad, sino que 'tendenciosamente' - pero artísticamente- la interpretó, yendo más allá de los aspectos puramente visibles de la organización social del montuvio, hasta entrar en su universo legendario y mitíco ${ }^{7}$.

Gabriel García Márquez no se halla tan distante de estos principios. En un momento de reflexión, el escritor colombiano dice sobre su labor literaria: "El coronel no tiene quien le escriba, La mala hora y muchos cuentos de Los funerales de la Mamá Grande son libros inspirados en la realidad de Colombia... No me arrepiento de haberlos escrito... Por buenos o malos que parezcan, son libros que acaban en la última página» ${ }^{8}$. Añade luego algunos comentarios que aclaran el cambio en su narrativa. Dice: «La reflexión sobre mi propio trabajo (me hizo cambiar). Una larga reflexión, para comprender al fin que mi compromiso no era con la realidad política y social de mi país, sino con toda la realidad de este mundo y del otro, sin preferir ni menospreciar ninguno de sus aspectos» ${ }^{9}$. Cuadra y García Márquez creen que «el deber del escritor y el deber del revolucionario es el de escribir bien» ${ }^{10}$.

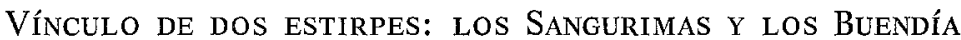

Cien años y Los Sangurimas son, respectivamente, las obras más representativas de García Márquez y de Cuadra. A pesar de las diferencias de estilo y técnicas de narración, un vínculo clarísimo une a sus novelas. En ambas se nos entrega viva, como ya se anotó, la figura de un patriarca

7. Narradores ecuatorianos, pp. xxxvi-xxxviI.

${ }^{8}$ Plinio A. Mendoza, El olor de la guayaba. Conversaciones con Gabriel García Márquez (Barcelona: Editorial Bruguera, S. A., 1983), p. 82.

9 Mendoza, pp. 82-83.

${ }_{10}$ Mendoza, p. 84. 
fundador y la gesta de su estirpe. Además de este eje fundamental que enlaza a Cien años y a Los Sangurimas, existen otros elementos o lazos visibles de importancia.

Estos elementos se relacionan con lo que caracteriza el mundo y el ambiente patriarcal en ambas novelas. Se resumen en los siguientes puntos: 1) el establecimiento de un espacio patriarcal; 2) la mitificación de la figura del patriarca; 3) la imposición machista del mundo masculino sobre el femenino; 4) la presencia del incesto, origen y causa de la tragedia final, y 5) la condenación del patriarca a la soledad o a la locura.

Se podría argüir que los elementos citados son comunes a cualquier novela que retrata patriarcas y que las remarcables semejanzas entre $L o s$ Sangurimas y Cien años son mera coincidencia. Sería absurdo sugerir que Cuadra influyese directamente en García Márquez. Sin embargo, considerar que Los Sangurimas es un posible antecedente literario de Cien años sí es factible. La novela de Cuadra encierra un auténtico valor literario, no siempre reconocido. En nuestra opinión, Cuadra, al escribir Los Sangurimas, ya se proyectó como un novelista de categoría universal. A1 menos, así lo reconoce Humberto E. Robles: "Los Sangurimas anuncia su insurgencia formal y temática, anuncia su vigencia y modernidad. Así, en 1934 se coloca a la vanguardia espiritual y técnica de promociones que se consolidarán después en la narrativa hispanoamericana» ${ }^{11}$.

\section{EL PATRIARCA: CONCEPTOS GENERALES}

Patriarca es el «nombre que se da al primer jefe de una familia». Por otro lado, por patriarcado se entiende «la organización social caracterizada por la preponderancia del padre sobre los otros miembros del grupo» o también por «el territorio regido por un patriarca» ${ }^{12}$. Moverse dentro de un mundo patriarcal implica vivir bajo ciertas condiciones o ideas rigentes que se mantienen vigentes. En un patriarcado hay una tendencia al autoritarismo o a la estratificación y se respeta la jerarquía. Además, se da énfasis a leyes establecidas por el varón. También se exige una lealtad unilateral, usualmente de la mujer con respecto al hombre o de los hijos con respecto a los padres. El éxito, los méritos individuales, la racionalidad y el honor se aprecian en gran manera. Finalmente, el hombre se desplaza con facilidad y trata de cambiar o dominar a la naturaleza ${ }^{13}$.

11 "Génesis y vigencia de Los Sangurimas», p. 91.

${ }^{12}$ The Random House Dictionary of the English Language (New York: Random House, Inc., 1966), p. 1057. La traducción es nuestra.

${ }_{13}$ Paul B. Dixon, "Matriarchy and Patriarchy in Machado de Assis' Dom Casmurro», en Discurso Literario, vol. I, núm. 2 (primavera 1984), pp. 189-191. 
Tanto Nicasio Sangurima y su estirpe como José Arcadio Buendía y la suya acatan estas normas en mayor o menor grado. Ambos jefes de familia se comportan respetando las características patriarcales fijadas.

\section{«Los Sangurimas» Y «Cren años»: PUntos DE CONTACTO}

La originalidad y el parecido entre las novelas de José de la Cuadra y Gabriel García Márquez puede observarse en el tratamiento que ellos dan separadamente al espacio, a la imagen del patriarca, al comportamiento sexual de los personajes masculinos y al final trágico que sufren sus patriarcas.

Ambos novelistas parecen preocuparse por establecer un espacio cerrado y mítico. «La Hondura», en Los Sangurimas, es un lugar extraño. Surge en medio de un terreno agreste, inhabitable, a la orilla de un río. «'La Hondura'... Vega en la orilla...», cuenta un residente del lugar, «no era más que un tembladeral... Cuando ño Sangurima se aconchambó con el Malo, compró el tembladeral... Y en seguida empezó a secarse el pantano y a brotar tierra solita... Mismamente como cuando cría carne en una herida» (Narradores, p. 271). Este espacio emerge de la nada, en un ambiente húmedo y sobrecogedor.

Macondo, en Cien años, nace también bajo circunstancias extraordinarias; está en medio de una selva tropical. Es una aldea rodeada de ciénagas y suelo hostil, junto a un río. «Una noche, después de varios meses. de andar perdidos por entre los pantanos..., acamparon a la orilla de un río cuyas aguas parecían un torrente de vidrio helado... José Aureliano Buendía soñó esa noche que en aquel lugar se levantaba una ciudad ruidosa con casas de paredes de espejo. Preguntó qué ciudad era aquella, y le contestaron con un nombre ... que tuvo en el sueño una resonancia sobrenatural: Macondo. Al día siguiente, convenció a sus hombres de que nunca encontrarían el mar. ... y allí fundaron la aldea» (Cien años, p. 28). Macondo es el resultado de un sueño; es un espacio iltusorio. También ha brotado de la nada.

Los patriarcas de «La Hondura» y de Macondo han escogido los bordes de un río para establecer su dominio. El río se convierte en señal de arraigamiento o de nacimiento de una estirpe. Las aguas del río marcan los confines del dominio patriarcal. Aún más, alejan a las aldeas del resto del mundo. "Macondo está rodeado de agua por todas partes», reclama José Aureliano Buendía. A lo que Ursula, su esposa, responde: «Aquí nos hemos de pudrir en vida sin recibir los beneficios de la ciencia» (Cien años, p. 19). La ciencia simboliza la presencia del mundo exterior. 
Para el narrador de Los Sangurimas, «La Hondura» es «una línea de leguas» que «se alargaba sobre el río de los Mameyes» y que «podía considerarse como el frente de la hacienda» (Narradores, p. 275). El Mameyes es la única ruta accesible a la civilización: Guayaquil. Además, el río es la marca física que circunscribe a un mundo sujeto a la voluntad de Nicasio. Tanto Cuadra como García Márquez consideraron similares referentes de la realidad, los que transformaron en ficción.

Las circunstancias previas a la fundación de las dos aldeas es otro elemento que vincula a ambas obras. Cuadra y García Márquez han escogido el homicidio como explicación y causa inmediata para el establecimiento de las estirpes en «La Hondura» y en Macondo. Los patriarcas Sangurima y Buendía abandonaron intempestivamente sus antiguas comarcas. El primero, cuando era un niño, fugó de Balao, junto a su madre; el segundo abandonó Riohacha, junto con su esposa.

En ambas novelas se cometió el delito para justificar los códigos patriarcales del honor. En Los Sangurimas, según cuenta el narrador, Nicasio Sangurima fue concebido como resultado de una violación. Su madre, nativa de Balao, fue seducida por un gringo. Para salvar el honor de la familia, un tío de Nicasio vengó la ofensa. Después del alumbramiento, la madre, quien todavía amaba a su ofensor, cometió un fratricidio. «En cuanto se alzó de la cama, fue a ver a mi tío. Lo topó solo. Se acomodó bien. Le tiró un machetazo por la espalda y le abrió la cabeza como coco» (Narradores, p. 268). Temerosa de sufrir un horrible castigo familiar, fugó de Balao, llevando consigo a su hijo. En busca de paz y nuevas tierras, llegó a «La Hondura», lugar que con el tiempo se convertiría en el patriarcado de Nicasio. «Cuando mi mamá me dejó para irse al cielo, yo era mocetón no más. Pero, claro, era un Sangurima enterito, sin que me faltara un pelo... En seguida empecé a mandar» (Narradores, p. 280).

La llegada de José Arcadio Buendía a Macondo fue distinta, pero la causa que lo llevó hasta allí fue un homicidio. En Riohacha, su aldea natal, José Arcadio se vio obligado a defender su virilidad ofendida. Se le acusó en el pueblo de no haber consumado el matrimonio por impotencia. "Y soltó el rumor de que Ursula (su esposa) seguía virgen un año después de casada, porque su marido era impotente» (Cien años, p. 25). Durante una pelea de gallos, Prudencio Aguilar, el contrincante suyo, lo ofendió públicamente. José Arcadio, herido en su amor propio (código patriarcal), citó a duelo al ofensor. En poco, lo atravesó con «la lanza cebada de su abuelo» (Cien años, p. 26). Atormentado por la culpabilidad y la extraña reaparición del muerto en su propia casa, decidió abandonar Riohacha. «Está bien, Prudencio —le dijo (José Arcadio)—. Nos iremos de este 
pueblo, lo más lejos que podamos, y no regresaremos jamás» (Cien años, p. 27). Así estableció Macondo y se formó la estirpe de los Buendia.

Otra relación de vínculo entre Los Sangurimas y Cien años se observa en el tratamiento mítico de la figura del patriarca. Cuadra concede a su protagonista atributos de personaje legendario. «Los madereros de los desmontes aledaños encontraban en los presuntos hechos del viejo Sangurima tema harto para sus charlas» (Narradores, p. 268). Nicasio es un símbolo de la naturaleza. El narrador lo compara con un árbol montuvio, el matapalo. Además, Nicasio goza de una perenne juventud. "Yo soy de madera incorruptible», afirma el mismo (Narradores, p. 266). Igualmente, sus ojos tienen poderes de hechicero, cuya pupila «era verdosa, cristalina, con el tono tierno de los brotes de caña de azúcar» (Narradores, p. 266). No es un ser real; es de leyenda. Nadie logra tampoco fijar su edad; si alguien lo hace, le asignan más allá de los cien años. «Ño Nicasio es viejísimo. ... más que el matapalo de los Solises» (Narradores, p. 270).

Pero hay un don mayor que caracteriza a Nicasio Sangurima y que lo comparte con José Arcadio Buendía de Cien años: la facultad de hablar con los muertos. Durante el velorio de Ceferino, Nicasio Sangurima pidió que le dejaran solo con el fallecido. Al cabo de un rato, los asistentes del velorio escucharon un animado diálogo entre Nicasio y el difunto. «De repente oímos que Ceferino también hablaba y reía. No entendíamos nada. ... Tenía al lado al muerto, abrazado» (Narradores, p. 269). En otra ocasión, Nicasio habla con un enterrado. Esta vez hay una fortuna de por medio. «Fue y le dijo a la candela: ¿¿Qué se te ofrece?' La llama se hizo un hombre y le dijo: 'Yo soy el mentado Rigoberto Zambrano, que viví por estos lados hace un mundo de años. Tengo una plata guardada que es para vos. Sácala.' No Sangurima dijo que bueno» (Narradores, p. 272). El Sangurima no teme comunicarse con ellos porque los conoce (Narradores, p. 275).

De otro lado, el patriarca Buendía igualmente es un ser raro. Su capacidad para asimilar e interpretar nuevos inventos sobrepasa a la del individuo ordinario. «José Arcadio Buendía, cuya desaforada imaginación iba siempre más lejos que el ingenio de la naturaleza, y aun más allá del milagro y la magia, pensó que era posible servirse de aquella invención inútil» (Cien años, p. 9). Nadie lo entiende, excepto aquel que también tuviera capacidad sobrenatural para intuir las cosas. Hay otro como él: Aureliano Buendía, su hijo. «El pequeño Aureliano, a la edad de tres: años; entró a la cocina en el momento en que ella (Ursula, su madre) retiraba del fogón y ponía en la mesa una olla de caldo hirviendo. El niño, perplejo en la puerta, dijo: 'Se va a caer.' La olla estaba bien puesta en: el centro de la mesa, pero tan pronto como el niño hizo el anuncio, inició 
un movimiento irrevocable hacia el borde, como impulsada por un dinamismo interior, y se despedazó en el suelo» (Cien años, p. 21). Esta facultad de clarividente en Aureliano Buendía se repite distintamente en años posteriores, por ejemplo, cuando presagia su propia muerte, que no se cumple. El coronel Aureliano Buendía mantiene la tradición de mago y alquimista de su padre; se dedica a diseñar pescaditos de oro, hasta el día de su muerte frente al castaño del patio de su casa. "Mientras orinaba trató de seguir pensando en el circo, pero ya no encontró el recuerdo. Metió la cabeza entre los hombros, como un pollito, y se quedó inmóvil» (Cien años, p. 229). Lo mítico, en el coronel Aureliano, no se limita a eso de vivir cien años y morir de vejez. El participó en treinta y dos guerras civiles y las perdió todas.

El patriarca mayor, José Arcadio Buendía, por otro lado, acaba comunicándose con Prudencio Aguilar, el difunto, a quien él mismo había asesinado en su juventud. Prudencio Aguilar lo acompaña hasta la fecha en que el patriarca fallece. «Era Prudencio Aguilar quien lo limpiaba, le daba de comer y le llevaba noticias espléndidas de un desconocido que se llamaba Aureliano y que era coronel en la guerra» (Cien años, p. 124). E1 eco del patriarca de Los Sangurimas repercute lejanamente en las páginas de Cien años.

Otro elemento patriarcal importante es el comportamiento sexual masculino y la fascinación constante de los Sangurima y de los Buendía por el incesto. La propagación exuberante del linaje se observa en ambos mundos patriarcales. En Los Sangurimas, la procreación es una demostración de dominio y orgullo machista. Nicasio hace alarde de su estirpe. Para él, los Sangurima son «Gente de bragueta, con las cosas puestas en su sitio» (Narradores, p. 274). El número de hijos es incontable. La cantidad es similar a las cuentas de los granos de una mazorca de maíz. La actitud arrogante del progenitor se une al espacio que se halla bajo su «bragueta». "En el caserío de 'La Hondura' regía un sistema patriarcal de vida, condicionado por el mandato ineludible del abuelo Sangurima, cuya autoridad omnipotente nadie se atrevía a discutir. ... Varios de los hijos y de los nietos adultos del viejo gobernaban negocios cuya clientela se reclutaba entre la parentela y la peonada» (Narradores, p. 295).

Donde impera la jerarquía de un patriarca, la mujer se reduce a órgano reproductor. Ella es pasiva y acata los deseos y voluntad del varón. Las esposas y las concubinas de los hijos de Nicasio ejemplifican esto. La esposa de Ventura «era una mujercita retaca, ancha de caderas, con un vientre enorme y de una proliferidad de cuy» (Narradores, p. 282). Los veinticuatro hijos que tuvo en veinticuatro años de casada son indicadores claros del papel que ella desempeña en la familia. 
De otro lado, la semejanza de Cien años con Los Sangurimas, en cuanto se refiere al excesivo machismo, es menor. García Márquez se preocupa menos por la promiscuidad masculina que por la femenina. El patriarca José Arcadio Buendía tiene únicamente tres hijos. En ningún momento del relato se alude a la promiscuidad de este personaje. Son sus hijos quienes establecen relaciones extramatrimoniales. El más promiscuo de todos es el coronel Aureliano Buendía. Se dice que tuvo dieciocho hijos ilegítimos en dieciocho mujeres distintas.

La mujer aparece bajo una luz más positiva. Contrario a la mujer retratada por Cuadra, la de García Márquez es agresiva y gozadora; ella satisface al varón tanto como se satisface a sí misma (Ursula, Amaranta, Meme, Amaranta Ursula, etc.). Como ha observado algún crítico, García Márquez mantiene una actitud satírica, lúdica, ante el machismo ${ }^{14}$. Petra Cotes es una mujer que carece de los prejuicios morales que afligen a Fernanda, por ejemplo. En Cien años, como to ha confirmado el propio novelista, las mujeres y los hombres tienen una función establecida; algunos aseguran la continuidad del linaje; otros no (los José Arcadios frente a los Aurelianos) ${ }^{15}$.

Los Sangurimas es un caso distinto. Todos los hijos legítimos e ilegítimos y los nietos de Nicasio Sangurima llevan una actitud negativa hacia la mujer. No la respetan. Ella es para aquel que se la lleva primero. «La mujer no es de naidien, sino del primero que la jala. Mismamente como una vaca alzada. Hay que cogerla como sea. A las buenas o a las malas» (Narradores, p. 297). Esta es la filosofía patriarcal que reina en «La Hondura».

Un tema de mayor relevancia dentro del contexto sexual, en ambas novelas, es el del incesto. Cuadra y García Márquez utilizan el incesto como el eje que mueve los incidentes de la acción. De hecho, la trama de ambas obras se entreteje en base al castigo del incesto. En Los Sangurimas, los «Rugeles» desean casarse con sus primas, «las tres Marías», sin escatimar las consecuencias de sus acciones. Ventura, el padre de las tres Marías, se interpone a la voluntad de sus sobrinos. Esto causa el rapto de una de ellas y su horrible muerte. María Victoria es abandonada en medio de la selva, desnuda y con su sexo traspasado por una rama de árbol.

Es el quebrantamiento del tabú, el incesto, el que causa el confrontamiento final. "Se historiaba a las gentes Sangurimas. Se daba, incluso aumentada, la lista de sus actos de horror. Se mostraba su genealogía encharcada de sangre, como la dinastía de salvajes señores» (Narradores,

\footnotetext{
${ }^{14}$ Levine, p. 130.

${ }^{15}$ Mendoza, pp. 108-109.
} 
p. 303). Las autoridades, el mundo exterior a la hacienda, rompen con el círculo cerrado de la aldea para destruir el patriarcado establecido. Los «Rugeles», quienes desde un principio se hallan destinados al castigo, ya que han violado las leyes naturales del tabú, sucumben ante la justicia poética que les espera. Aun las leyes patriarcales que prevalecen en «La Hondura» no logran protegerlos. Nicasio termina afligido en la impotencia. Su autoridad ha perdido valor. El también sucumbe bajo la fuerza de la maldición del incesto.

$\mathrm{Su}$ imagen mítica, predominante al principio, se desmitifica. Se nos retrata a un anciano desesperado y dolido por la pérdida de sus nietos predilectos. Por eso insulta con saña a su hijo Terencio, el "padre cura». «Usté será todo lo cura que quiera... No me opongo... Pero aquí, en confianza, le voy a decir que pa mí, si Ventura es un pendejo, usté es otro más grande... Más grande» (Narradores, p. 308). La culpabilidad inflige en él un autocastigo. Nicasio Sangurima nació de la violencia y también termina entre la violencia. El ciclo se completa. Hay un movimiento circular. La semejanza con Cien años se acentúa bajo este paradigma.

En Cien años, la tentación y consumación del incesto determinan el nacimiento y la destrucción de la estirpe de los Buendía. García Márquez, al igual que Cuadra, usa el incesto como asunto central de la novela. Este tema sostiene y mueve la acción de la novela. Todos los personajes, incluso los secundarios, en menor o mayor grado, se ven afectados por él. Pilar Ternera, por ejemplo, es amante de los primogénitos de los Buendía (incesto informal). José Arcadio y el coronel Aureliano conciben hijos en ella. No hay que olvidar que Ursula y el patriarca José Arcadio Buendía son primos.

El tabú no se respeta desde los orígenes y la estirpe está condenada a perecer. "Aunque su matrimonio era previsible desde que vinieron al mundo, cuando ellos expresaron la voluntad de casarse sus propios parientes trataron de impedirlo» (Cien años, p. 25). Los Buendía están condenados a vivir acosados por el temor de engendrar hijos monstruosos, «con cola de cerdo» ${ }^{16}$.

A través de las cinco generaciones (cuatro generaciones en Los Sangurimas) existe un constante juego ante la tentación y el rechazo del incesto. Hay otra dicotomía que es típica del comportamiento de los Buen-

${ }^{16}$ Para la definición de incesto y el concepto de tabú véanse: Michel Foucault, The History of Sexuality. Volume I: Introduction, trans. de Robert Hurley (New York: Vintage Books, 1980), pp. 38, 109-110, 113, 129-130; Jean H. Hanstrum, Sex and Sensibility. Ideal and Erotic Love from Milton to Mozart (Chicago and London: The University Press, 1980), pp. 42-43, 55-56, 56-58, 82-83, 179-180, 266-267; Levine, pp. 108-109. 
día ante el incesto: el temor y la fascinación por él. Los personajes que lo sienten (José Arcadio y Rebeca, hermana adoptiva; Amaranta y Aureliano José; Amaranta y José Arcadio; Amaranta Ursula y Aureliano) padecen de: una soledad imperecedera, un terror horrible de engendrar seres con cola de cerdo; sufren de un arrepentimiento profundo y ansias de muerte. «José Arcadio le (a Rebeca) acariciaba los tobillos con la yema de los dedos, y luego las pantorrillas y los muslos, murmurando: 'Ay, hermanita; ay, hermanita.' Ella tuvo que hacer un esfuerzo sobrenatural para no morirse» (Cien años, p. 85). Nadie se escapa de la fuerza de este imán bipolar.

El incesto le atrae a Amaranta; le fascina. Ante la llegada de su sobrino Aureliano José, ella siente un gran miedo. Trata de evitar cualquier contacto con él; pero la fuerza del imán es superior. Por poco se subyuga al impulso prohibido. "Desde aquella noche se reiniciaron las sordas batallas sin consecuencias que se prolongaban hasta el amanecer. 'Soy tu tía', murmuraba Amaranta agotada. 'Es casi como si fuera tu madre, no sólo por la edad, sino porque lo único que me faltó fue darte de mamar.' Aureliano escapaba al alba y regresaba a la madrugada siguiente» (Cien años, p. 132). Tía y sobrino se acercan a él, pero luego lo rechazan.

Hay un pago obligado en este ciclo. Por rechazar el incesto, los hombres y las mujeres terminan en medio de una triste soledad. Así, la estirpe se va secando, como se seca Macondo. El desbalance que trae la constante presencia del incesto va minando los espíritus de sus habitantes hasta llevarles al olvido. El incidente final incestuoso tiene lugar en la casa de los Buendía y envuelve a Amaranta Ursula y a su sobrino Aureliano. El resultado es fatal. La estirpe pagará con la extinción y el nacimiento de un niño con cola de cerdo, el cual es comido por las hormigas.

El castigo por quebrantar el tabú es la muerte. La novela empezó con una muerte y se cierra también con una muerte. Así, el patriarcado de los Buendía sufre tanta destrucción y desbalance como el patriarcado de los Sangurimas. El parentesco es evidente, aunque las técnicas de narración en cada obra sean distintas.

Se ha mencionado, en otro lugar de este ensayo, que existe un último punto de contacto entre Cien años de soledad y Los Sangurimas. Con acierto, este punto se halla vinculado al tema del que tratan ambas novelas. Se ha explicado algo en el apartado anterior. Los patriarcas Buendía y los Sangurimas terminan en la locura o en la soledad. Su patriarcado desaparece o se convierte en una prisión simbólica, consecuencia de la pérdida de control sobre el espacio y el tiempo que ellos rigen.

En Cien años, José Arcadio Buendía se abandona a la alquimia, a la invención, para evadir el temor y la culpa, consecuencia del incesto. Gra- 
dualmente va perdiendo contacto con la realidad de su patriarcado. Interesantemente, dedica parte de su vida a descifrar el manuscrito de Melquíades, que no logra traducirlo; es la saga de su propia familia. Si hubiera logrado descifrarlo, se habría autodestruido. El refugio para él es la soledad. En la soledad, pierde toda autoridad. Su patriarcado ha continuado el curso iniciado por él mismo.

E1 espacio ilusorio fundado desaparece bajo la fuerza del viento y la maldición de su estirpe. Su locura y obsesión final es «sana». Son la soledad intelectual. Es soñarse en su propio sueño. La soledad es la misma que aqueja a don Quijote antes de morir. Es la soledad que produce el juego de espejos en Las meninas de Velázquez. "José Aureliano Buendía se consolaba con el sueño de los cuartos infinitos. Soñaba que se levantaba de la cama, abría la puerta y pasaba al otro cuarto igual, con la misma cama de cabecera de hierro forjado, el mismo sillón de mimbre y el mismo cuartito de la Virgen de los Remedios en la pared del fondo. De ese cuarto pasaba a otro exactamente igual, cuya puerta abría para pasar a otro exactamente igual, y luego a otro exactamente igual, hasta el infinito» (Cien años, p. 124).

Nicasio Sangurima, por otro lado, es el tipo de patriarca tradicional. Se halla acosado por sus propias reglas establecidas. Son reglas que permiten el incesto, la violencia, el dominio sobre seres que respetan una jerarquía incondicional. A él también le acosa la soledad, pero es una soledad distinta. No es la producida por la culpa ni por el remordimiento de crímenes perpetrados o permitidos. Es la soledad del patriarca que rige. Es el aislamiento del patriarca que se siente abandonado bajo su propia fuerza y poder. El mayor temor que siente Nicasio es el de ser desmitificado.

Las escenas finales de la novela muestran la debilidad de un patriarca. El afecto que Nicasio ofrece a sus nietos es auténtico. Expresa sinceridad para defenderlos, pero el Sangurima sabe que ellos han quebrantado las leyes que van más allá de los límites del espacio cerrado de «La Hondura». Los «Rugeles» son el producto de su propio quehacer. Son un reflejo de su autodestrucción.

El patriarcado fundado por él, tarde o temprano tiene que abrir las puertas para integrarse a la corriente de los Mameyes. El fracaso es permanente. La integridad de su patriarcado se ha desintegrado. Lo único que le queda a Nicasio Sangurima es el símbolo de su existencia. Al igual que José Arcadio Buendía, de Cien años, pierde la razón. Pero su locura no es «sana». Es impávida y dañosa:

Inició un gesto lento, con la mano hacia lo alto:

-Grande como un matapalo, amigo... 
En los ojos alagartados de Don Nicasio la luz de la locura prendió otro fuego... (Narradores, p. 308).

\section{COMENTARIO Final}

Los Sangurimas y Cien años de soledad innegablemente guardan un parentesco sintomático. En estas obras, José de la Cuadra y Gabriel García Márquez usan el mismo referente: la realidad «mágica» de sus países de origen: Ecuador y Colombia. Ambos autores retratan pueblos que son la cuna de dos estirpes distintas. En ellas rigen dos patriarcas, Nicasio Sangurima y José Arcadio Buendía, quienes imparten similares valores patriarcales en mundos cerrados. Los personajes patriarcales han escogido lugares parecidos para fundar sus aldeas: cerca del mar y junto a un río.

Por otro lado, ambos novelistas han escogido similares circunstancias iniciales para desarrollar la trama de sus novelas: un homicidio. Finalmente, Cuadra y García Márquez usan el incesto como asunto eje que mueve la acción de sus novelas.

$\mathrm{Si}$ se asume que toda literatura en formación mantiene temas o asuntos latentes que han sido heredados o asimilados por el subconsciente colectivo de promociones literarias anteriores, podría explicar, en parte, la asombrosa relación temática percibida en Los Sangurimas y Cien años. Ambas novelas han tratado el tema del patriarca bajo distintos matices y técnicas. En nuestros días, este tema está vigente - pensemos en El otoño del patriarca (1975), del mismo García Márquez, y La casa de los espíritus (1982), de Isabel Allende, para citar dos-. También estuvo vigente en 1934 y en 1967, cuando Cuadra y García Márquez publicaron sus novelas. Ambos novelistas consideraron a sus patriarcas símbolos del régimen antiguo y obsoleto. Es posible que ambos, García Márquez y Cuadra, desearan mitigar el subconsciente latinoamericano suyo, atormentado por las injusticias sociales insoportables de esa época. Quizás, el tema debió de ser exorcizado para promover un nuevo orden social más justo.

Si ésa era la intención que motivó a José de la Cuadra a escribir Los Sangurimas, definitivamente la continuó Gabriel García Márquez en Cien años. Pero el tema todavía no ha desaparecido. En la actualidad, se escribe y se estudia a los patriarcas de América Latina. Quizás es un tema en transformación para la transformación ${ }^{17}$.

${ }_{17}$ Angel Rama, Los dictadores latinoamericanos (México: Fondo de Cultura Económica, 1976), capítulo IV, pp. 52-63. 
